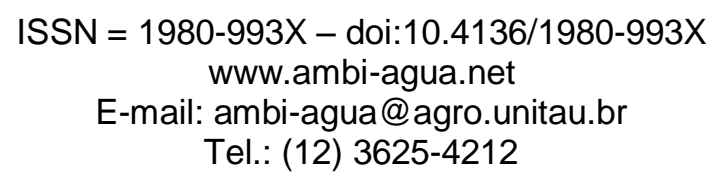

\title{
Efeito do uso e ocupação do solo na qualidade da água na micro- bacia do Córrego Banguelo - Contagem
}

\author{
(http://dx.doi.org/10.4136/ambi-agua.962) \\ Patrícia Procópio Pontes ; Andréa Rodrigues \\ Marques $^{2}$; Guilherme Fernandes Marques ${ }^{3}$ \\ ${ }^{1}$ Departamento de Química, Centro Federal de Educação Tecnológica de Minas Gerais, Belo Horizonte, MG, \\ e-mail: patricia@des.cefetmg.br, \\ ${ }^{2}$ Departamento de Ciência e Tecnologia Ambiental, Centro Federal de Educação Tecnológica de Minas Gerais, \\ Belo Horizonte, MG, e-mail: andrearmg@ gmail.com, \\ ${ }^{3}$ Departamento de Engenharia Civil, Centro Federal de Educação Tecnológica de Minas Gerais, Belo \\ Horizonte, MG, e-mail: gmarques@ civil.cefetmg.br
}

\section{RESUMO}

A micro-bacia do córrego Banguelo da sub-bacia Bom Jesus contribui, junto com outras, para formação do reservatório da Pampulha, cuja poluição é considerada um dos grandes problemas ambientais do município de Belo Horizonte. O presente trabalho teve como objetivo avaliar o efeito do uso e ocupação do solo na qualidade da água num ciclo sazonal em diferentes pontos da micro-bacia. Para o monitoramento da qualidade da água, os parâmetros analisados foram: $\mathrm{pH}$, turbidez, oxigênio dissolvido, fosfato, nitrato, nitrogênio total, temperatura, $\mathrm{DBO}_{5}, \mathrm{DQO}$, sólidos totais e coliformes termotolerantes. Foi realizado, ainda, um levantamento florístico e das condições de ocupação do solo nas margens do córrego. A partir dos resultados do monitoramento, foram calculados os índices de qualidade da água (IQA ${ }_{\mathrm{NSF}}$ ) e identificados os pontos com maior grau de poluição. A análise do IQA indicou que a qualidade da água oscilou entre média e ruim no período seco, tendo-se observado a melhoria da qualidade da água para boa e média no período chuvoso. A deterioração da qualidade das águas ocorreu devido ao lançamento de efluente industrial e esgoto das áreas urbanizadas, com ocorrência de níveis baixos de oxigênio dissolvido, alta concentração de matéria orgânica e nutrientes. Nas áreas com vegetação, observou-se diminuição na concentração de poluentes (principalmente nitrato e fosfato), indicando a importância da manutenção da vegetação ripária como medida de melhoria da qualidade das águas na região. A minimização da poluição neste córrego pode melhorar a qualidade da água da sub-bacia e, consequentemente, contribuir para deseutrofização do reservatório da Pampulha.

Palavras-chave: Qualidade da água, uso e ocupação do solo, índice de qualidade da água.

\section{Effect of land use and occupation in water quality in the micro-basin of Banguelo Creek - Contagem}

\section{ABSTRACT}

The Banguelo creek micro-basin, in the sub-basin Bom Jesus contributes for the formation of Pampulha reservoir, along with other contributors. The pollution in this reservoir is considered one of the major environmental problems of the city of Belo Horizonte. This paper evaluated the effect of land use and occupation in Banguelo Creek on its water quality, considering the seasonal cycle in several points of the micro-basin. The 
PONTES, P. P.; MARQUES, A. R.; MARQUES, G. F. Efeito do uso e ocupação do solo na qualidade da água na micro-bacia do Córrego Banguelo - Contagem. Ambi-Agua, Taubaté, v. 7, n. 3, p. 183-194, 2012. (http://dx.doi.org/10.4136/ambi-agua.962)

analyzed parameters for monitoring the water quality were: $\mathrm{pH}$, turbidity, dissolved oxygen, phosphate, nitrate, total nitrogen, temperature, $\mathrm{BOD}_{5}, \mathrm{COD}$ and thermotolerant coliforms. The results were analyzed based on a floristic survey and on land occupation conditions in the micro-basin. Water quality index $\left(\mathrm{WQI}_{\mathrm{NSF}}\right)$ was calculated and the points with the highest degree of pollution were identified. Analysis of WQI indicated that the water quality fell in the classes "average" and "bad" during dry season, with improvement for "good" and "average" in the rainy season. The deterioration of water quality was attributed to the discharge of industrial effluent and sewage that caused low levels of dissolved oxygen, high concentration of organic matter and nutrients. In areas with vegetation, a decrease in the concentrations of pollutants (mainly nitrate and phosphate) was observed, indicating the importance of maintaining riparian vegetation to improve the water quality in the region. The decrease in the pollution level of this creek could improve the water quality in the region, contributing to the eutrophication reduction of Pampulha reservoir.

Keywords: Water quality, land use and occupation, water quality index.

\section{INTRODUÇÃO}

A qualidade das águas depende de vários aspectos, dentre os quais se destacam os usos antrópicos (retiradas e lançamentos nos corpos d'água) e a variabilidade natural das vazões. O seu estudo é fundamental para a avaliação das suas possibilidades de utilização. A região metropolitana de Belo Horizonte localiza-se em partes altas das bacias dos rios das Velhas e do Paraopeba. O rio das Velhas é um dos mais importantes afluentes em termo de volume de água do rio São Francisco, que é um dos maiores do Brasil. Segundo dados do IBGE (2000), o rio das Velhas foi considerado o mais poluído do estado de Minas Gerais, em parte porque sua bacia possuia uma população humana total maior que 4,5 milhões de pessoas, e o esgoto doméstico e resíduos industriais das cidades eram apenas parcialmente tratados. O esgoto de 3,2 milhões de pessoas nesta região era coletado, mas apenas $27,5 \%$ eram essencialmente tratados. Em muitas áreas rurais e suburbanas, a população que vive no entorno do rio usa a água para fins domésticos, higiene e lazer. A consequência da deterioração da qualidade da água é a restrição ao uso potencial de um manancial. No caso de uso para a irrigação, a utilização de uma água de baixa qualidade pode acarretar problemas de operacionalização em sistemas de irrigação, neste caso, ocorre o risco de contaminação dos alimentos irrigados, comprometendo a qualidade do produto e principalmente a saúde humana (Franco et al., 2006).

A bacia hidrográfica do rio das Velhas tem como seus principais afluentes, responsáveis pelas maiores cargas poluidoras, os ribeirões Arrudas e Onça. Suas bacias hidrográficas compreendem parte dos territórios de Belo Horizonte, de Contagem e uma parte do município de Sabará, na porção de jusante da bacia Arrudas. A bacia do ribeirão do Onça em unidades menores destaca-se num terceiro nível de drenagem na bacia que contribui para o reservatório da Pampulha. A poluição da bacia da Pampulha é considerada um dos grandes problemas ambientais do município de Belo Horizonte. Inúmeras iniciativas têm ocorrido para recuperação da região, entretanto o processo de expansão urbana sem planejamento nas micro-bacias contribui para o assoreamento do reservatório da Pampulha, eutrofização de suas águas e destruição das matas ripárias (PROPAM, 2001). Segundo Friese et al. (2010), o reservatório da Pampulha apresenta estratificação permanente, baixos teores de oxigênio e elevada concentração de nutrientes, culminando em elevada degradação ecológica. A presença de outros contaminantes, incluindo metais pesados é também verificada em índices considerados alarmantes por Friese et al. (2010), sendo ainda relatada 
PONTES, P. P.; MARQUES, A. R.; MARQUES, G. F. Efeito do uso e ocupação do solo na qualidade da água na micro-bacia do Córrego Banguelo - Contagem. Ambi-Agua, Taubaté, v. 7, n. 3, p. 183-194, 2012. (http://dx.doi.org/10.4136/ambi-agua.962)

em Sabino et al. (2004) e Rietzler et al. (2001), dentre outros. As sub-bacias de contribuição ao reservatório da Pampulha possuem cerca de $94 \mathrm{~km}^{2}$, estendendo-se pelos municípios de Belo Horizonte (44\%) e Contagem (56\%) e tendo como principais tributários diretos do reservatório os córregos Mergulhão, Tijuco, Bandeirantes, Ressaca, Bom Jesus ou Água Funda, Baraúna, Garças, AABB, Olhos d'Água ou Paracatu.

Embora alvo de grande número de estudos, o reservatório da Pampulha ainda carece de avaliações acerca do efeito sazonal das atividades antrópicas. O entendimento da variação sazonal da qualidade da água dos tributários do reservatório da Pampulha é importante no planejamento de medidas de intervenção. Nesse contexto, o presente trabalho teve como objetivo avaliar o efeito do uso e ocupação do solo na qualidade da água num ciclo sazonal em diferentes pontos da micro-bacia do córrego Banguelo na sub-bacia do Bom Jesus ou Água Funda. A avaliação da qualidade da água no córrego irá contribuir para um maior conhecimento de suas características e na identificação das principais fontes de degradação ambiental e de poluição, contribuindo para o banco de dados ambientais da Bacia da Pampulha.

\section{MATERIAIS E MÉTODOS}

\section{1. Área de estudo}

O córrego Banguelo (entre $19^{\circ} 51^{\prime} \mathrm{S} 44^{\circ} 03^{\prime} \mathrm{O}$ e $19^{\circ} 50^{\prime} \mathrm{S} 44^{\circ} 02^{\prime} \mathrm{O}$ ) alimenta a sub-bacia do córrego Bom Jesus ou Água Funda (Figura 1), na região de Contagem, integrando-se ao Córrego Ressaca em Belo Horizonte na bacia do Ribeirão do Onça - Minas Gerais. Os corpos d'água das sub-bacias da Pampulha foram classificados na Classe 2, segundo a resolução 357/05 do CONAMA, no entanto, devido à suas condições, incluindo-se a lagoa, encontraram-se fora dos padrões fixados para aquela Classe (PROPAM, 2001).

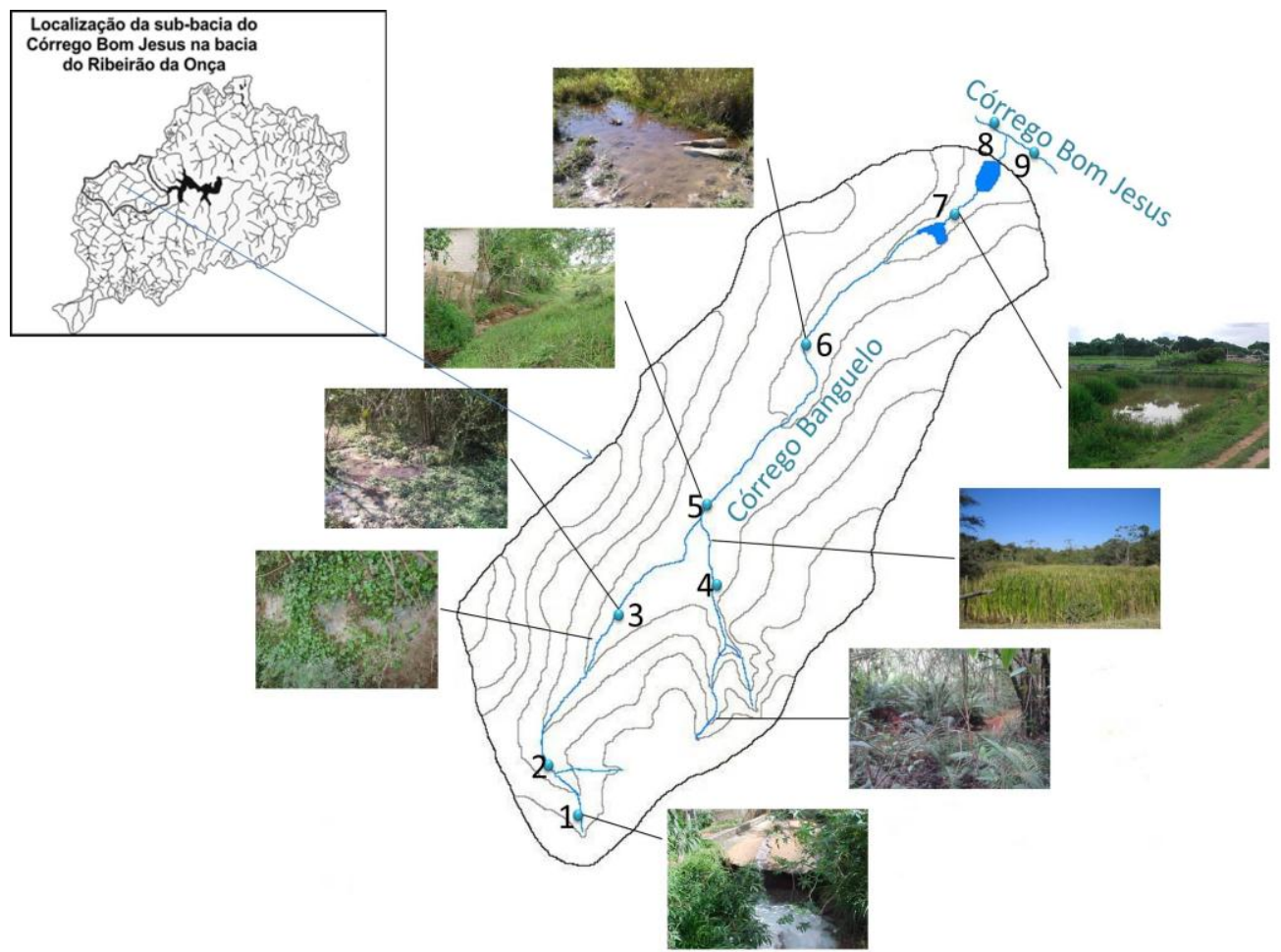

Figura 1. Localização dos pontos de monitoramento da água ( 1 a 9) na microbacia do córrego Banguelo - Contagem $\left(19^{\circ} 51^{\prime} \mathrm{S} 44^{\circ} 03^{\prime} \mathrm{O}\right.$ e $\left.19^{\circ} 50^{\prime} \mathrm{S} 44^{\circ} 02^{\prime} \mathrm{O}\right)$ na sub-bacia do córrego Bom Jesus. As fotos caracterizam alguns pontos de amostragem no curso d'água. 
Os solos residuais constituintes da superfície da bacia são provenientes de rochas granitognaissicas, o que lhes confere homogeneidade morfológica e susceptibilidade à erosão. A altitude média da bacia é de $850 \mathrm{~m}$, estando à superfície do reservatório da Pampulha a $801 \mathrm{~m}$; o ponto mais elevado a $1089 \mathrm{~m}$, no divisor de águas com o Córrego Água Branca (bacia do Ribeirão Arrudas). A declividade média da bacia situa-se na faixa de 10 a $20 \%$. Verificam-se as maiores declividades médias nas sub-bacias dos Córregos Sarandi, Mergulhão e Ressaca, com ocorrência de taxas superiores a 25\% em suas cabeceiras, e as menores na sub-bacia do Córrego Bom Jesus ou Água Funda, cuja predominância é inferior a $10 \%$. A região apresenta um clima mesotérmico (CWB de acordo com o sistema Köppen), com verões quentes e estação seca bem definida. A precipitação é maior no período de Setembro a Abril (primavera e verão) e as médias mínimas das temperaturas variam entre 13 e $19^{\circ} \mathrm{C}$ e as máximas entre 24 e $29^{\circ} \mathrm{C}$. Os dias mais frios coincidem com os meses de Maio a Agosto (inverno na região) (Figura 2).

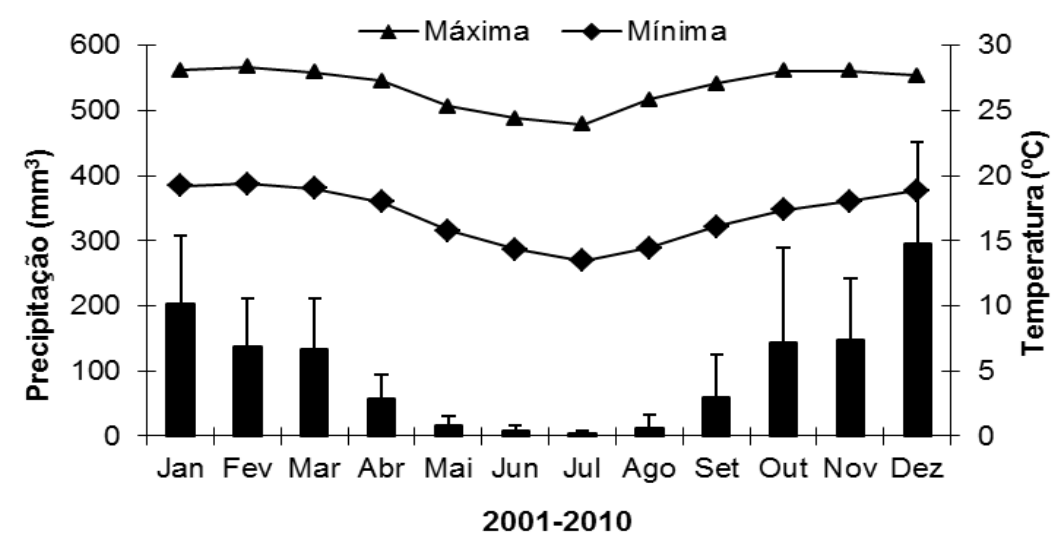

Figura 2. Diagrama do clima próximo à área de estudo entre os anos de 2001 e 2010: temperaturas médias, máximas e mínimas (linhas) e precipitação (barras), com dados obtidos da Estação Meteorológica da Pampulha - Belo Horizonte.

\subsection{Monitoramento da qualidade da água}

Para avaliação da qualidade da água, foram realizados trabalhos de campo com a identificação dos pontos mais adequados para a coleta de amostras. Foram selecionados nove pontos de monitoramento: seis pontos no próprio córrego Banguelo, um em seu afluente (ponto 4) e dois no córrego Bom Jesus (pontos 8 e 9) ( Figura 1).

Para o monitoramento da qualidade da água, que ocorreu durante um período de quase um ano (setembro de 2008 a julho de 2009), os parâmetros analisados foram: pH, turbidez, oxigênio dissolvido (OD), fosfato, nitrato, nitrogênio total, temperatura, demanda bioquímica de oxigênio $\left(\mathrm{DBO}_{5}\right)$, demanda química de oxigênio (DQO), sólidos totais e coliformes termotolerantes. As metodologias para as análises realizadas se encontram descritas no Standard Methods for Examination of Water and Wastewater (AWWA et al., 2005). A partir dos resultados do monitoramento, foram calculados os índices de qualidade da água e identificados os pontos com maior grau de poluição na micro-bacia.

\section{3. Índice de Qualidade da Água (IQA)}

Para determinar o índice de qualidade da água, foram estabelecidos alguns parâmetros pela National Sanitation Foundation (NSF) nos Estados Unidos, através de pesquisa com especialistas da área ambiental. Para cada parâmetro atribuiu-se um peso (wi) de acordo 
PONTES, P. P.; MARQUES, A. R.; MARQUES, G. F. Efeito do uso e ocupação do solo na qualidade da água na micro-bacia do Córrego Banguelo - Contagem. Ambi-Agua, Taubaté, v. 7, n. 3, p. 183-194, 2012. (http://dx.doi.org/10.4136/ambi-agua.962)

com sua importância para o índice de qualidade da água. Assim nove parâmetros foram considerados mais representativos: oxigênio dissolvido (wi $=0,17$ ), coliformes termotolerantes (wi $=0,15), \mathrm{pH}(\mathrm{wi}=0,12)$, demanda bioquímica de oxigênio (wi $=0,10)$, nitrato (wi $=0,10)$, fosfato total (wi $=0,10)$, variação de temperatura da água $(w i=0,10)$, turbidez (wi $=0,08)$ e sólidos totais $($ wi $=0,08)$. No caso do oxigênio dissolvido, determinase a porcentagem de oxigênio dissolvido em relação à concentração de saturação. Assim o IQA é calculado a partir do produto ponderado das qualidades da água correspondentes aos parâmetros.

\subsection{Caracterização do uso e ocupação do solo das margens do córrego}

A caraterização das diferentes formas de uso e ocupação do solo das margens do córrego e nascentes foi realizada através de observações in loco e registros fotográficos. Foram catalogadas as espécies vegetais observadas, e verificada a existência de possíveis focos de erosão e lançamentos de esgotos e efluentes industriais.

\section{RESULTADOS E DISCUSSÃO}

\subsection{Análise sazonal da qualidade da água}

Os resultados obtidos para a qualidade da água foram analisados baseando-se no atendimento aos valores recomendados pela resolução 357/05 do CONAMA para rios classe 2. Os valores médios de oxigênio dissolvido (OD) (Figura 3a), para os vários pontos de monitoramento apresentaram concentrações fora do recomendado, que é igual ou superior a 5 mg. $\mathrm{L}^{-1}$, indicando a presença de poluição no córrego. Pode-se observar que durante o período seco (maio a agosto) cerca de 6 pontos de monitoramento estiveram de acordo com o padrão da Resolução CONAMA ou muito próximos desse valor, enquanto no período chuvoso (setembro a abril) somente um ponto de monitoramento (ponto 7) apresentou valor acima de $5 \mathrm{mg} . \mathrm{L}^{-1}$. As maiores concentrações de OD foram nos pontos de monitoramento 4 e 7 (Figura 3a).

Os valores de $\mathrm{DBO}_{5}$ (Figura $3 \mathrm{~b}$ ) estiveram acima do padrão máximo de $5 \mathrm{mg} \cdot \mathrm{L}^{-1} \mathrm{em}$ todos os pontos de amostragem, tanto no período seco quanto no período chuvoso, tendo-se observado valores de $\mathrm{DBO}_{5}$ um pouco mais elevados no período chuvoso, provavelmente devido à contaminação proveniente de escoamento e drenagem pluvial que se reflete também nos valores de OD (Figuras 3a e 3b). Os valores de DQO (Figura 3c) foram mais elevados no ponto 1 que corresponde ao ponto de lançamento de efluente industrial no córrego. A partir do ponto de monitoramento 2, ocorre uma grande redução no valor de DQO no córrego. Em relação ao pH (Figura 3d), observou-se que os valores estiveram próximos de 7,0 no período seco e no período chuvoso e, na maioria dos pontos de monitoramento, apresentaram uma pequena redução no período de chuvas.

Para a turbidez (Figura 4a), foram observados valores inferiores a 100 UNT em todos os pontos nos meses de monitoramento, ou seja, em termos de $\mathrm{pH}$ e turbidez, o córrego está dentro da faixa padrão para a classe 2, segundo a resolução 357/05 do CONAMA. Não foi observada uma tendência de aumento da turbidez no período chuvoso, provavelmente devido à baixa vazão no córrego que deve ter favorecido a sedimentação de sólidos. Os resultados mostraram que foi possível atender ao limite máximo estabelecido pela Resolução CONAMA 357/05 para contagem de coliformes fecais ou termotolerantes para rio classe 2, que é de $1 \times 10^{3} \mathrm{NMP} .100 \mathrm{~mL}^{-1}$. No ponto 1 (período seco), que recebe lançamento de efluente industrial, e nos pontos 5 e 8 (período chuvoso), que se localizam próximos a áreas parcialmente urbanizadas, os valores médios estiveram acima desse valor (Figura 4b). 
A concentração de nitrato foi mais elevada no ponto de monitoramento 1, principalmente, nos meses secos, local que estava recebendo efluente industrial. Pode-se observar que os valores médios de nitrato no período chuvoso foram inferiores aos do período seco (Figura 4c). No entanto, os resultados obtidos para a concentração de nitrato (Figura4c) estiveram abaixo do limite máximo desejável (45 mg. $\mathrm{L}^{-1}$ de nitrato) em todos os pontos de monitoramento. A presença de baixas concentrações de nitrato pode indicar que o nitrogênio esteja presente na forma orgânica ou amoniacal. Foram observadas elevadas concentrações para o nitrogênio total em alguns pontos de amostragem, principalmente nos pontos 1,3 e 5 , com valores entre 150 e $330 \mathrm{mg} . \mathrm{L}^{-1}$. Os resultados indicam uma contaminação do córrego por esgotos domésticos e industriais, com concentrações de nitrato pequenas em comparação à de nitrogênio total, demonstrando a predominância das formas intermediárias do ciclo geoquímico (orgânica, de nitrito e de amônia), provenientes de dejetos orgânicos lançados ao ambiente.

Notou-se que praticamente todos os valores médios para a concentração de fosfato estavam acima do permitido segundo a resolução 357/05 do CONAMA $\left(\leq 0,025 \mathrm{mg}\right.$. $\left.\mathrm{L}^{-1}\right)$ para rios classe 2. Durante o período chuvoso foram obtidas as concentrações mais elevadas de fosfato (Figura 4d). Este aumento foi esperado considerando-se que o escoamento de áreas urbanas, agrícolas ou de matas pode contribuir para o aumento na sua concentração em cursos d'água (Xavier, 2005). A presença de concentrações de fosfato acima do valor estabelecido na resolução 357/05 do CONAMA no córrego Banguelo e no córrego Bom Jesus pode contribuir para o aumento da sua concentração no reservatório da Pampulha, contribuindo para a sua eutrofização.

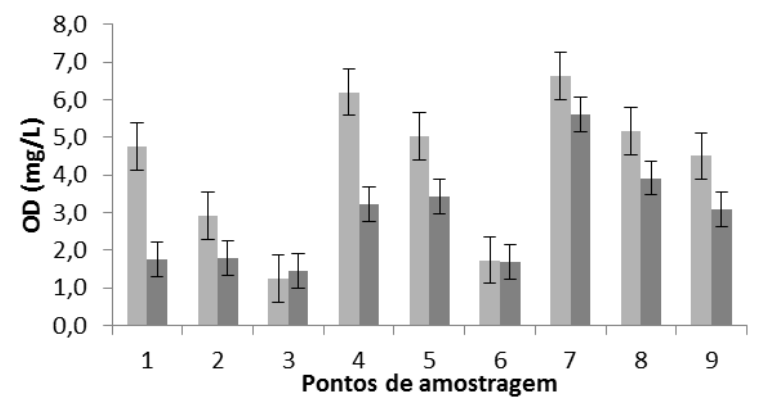

(a)

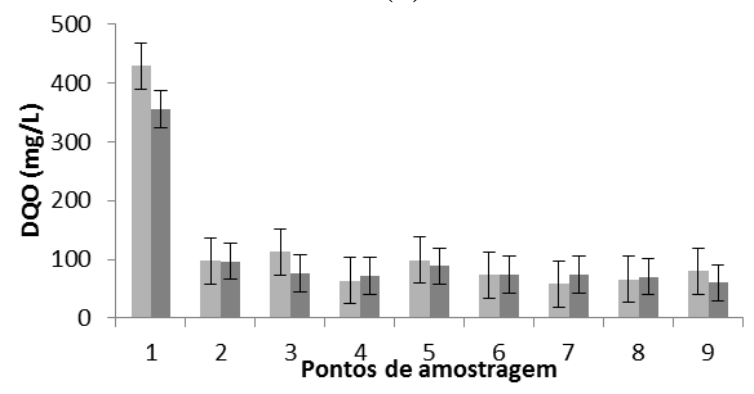

(c)

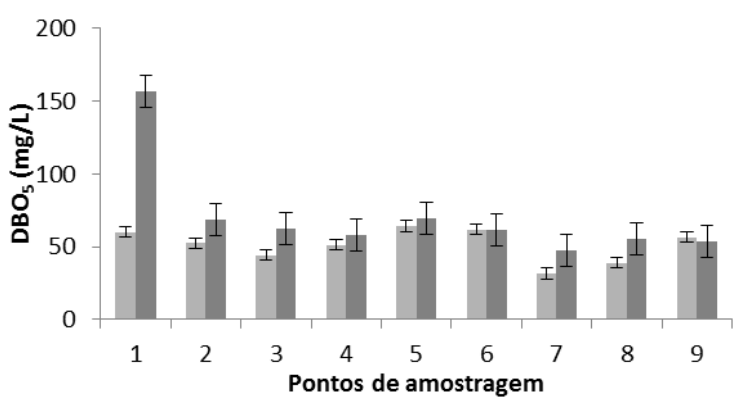

(b)

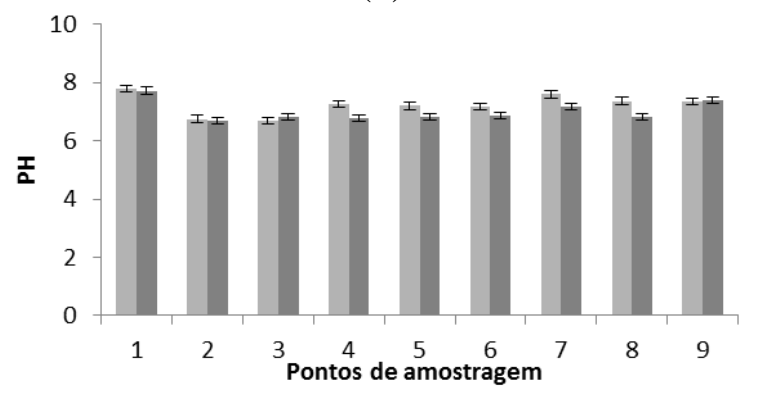

(d)

\section{Período seco Período chuvoso}

Figura 3. Valores médios de (a) OD, (b) $\mathrm{DBO}_{5}$, (c) DQO e (d) $\mathrm{pH}$ nos diferentes pontos de monitoramento na micro-bacia do Córrego Banguelo. 
PONTES, P. P.; MARQUES, A. R.; MARQUES, G. F. Efeito do uso e ocupação do solo na qualidade da água na micro-bacia do Córrego Banguelo - Contagem. Ambi-Agua, Taubaté, v. 7, n. 3, p. 183-194, 2012. (http://dx.doi.org/10.4136/ambi-agua.962)

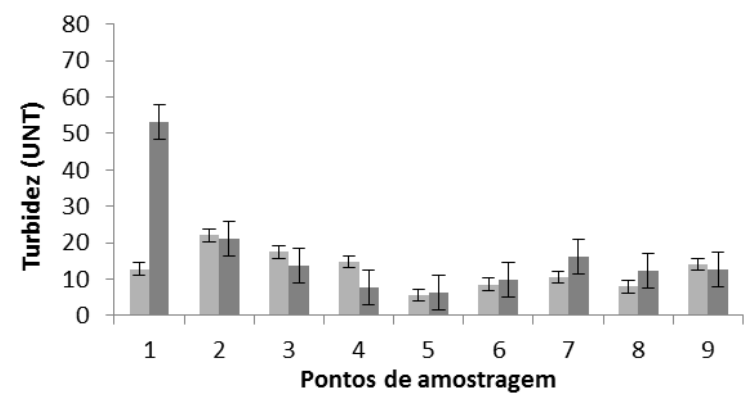

(a)

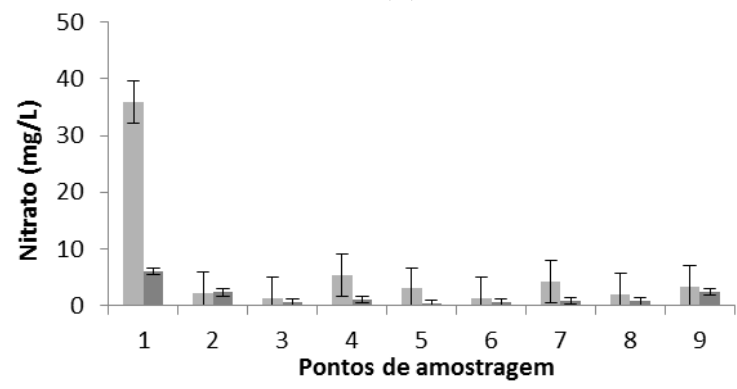

(c)

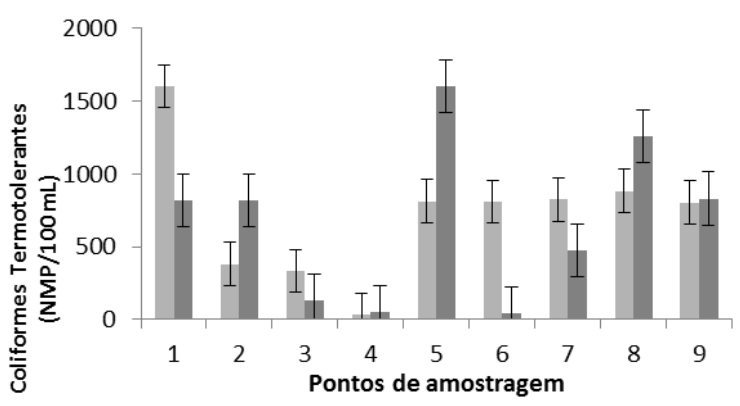

(b)

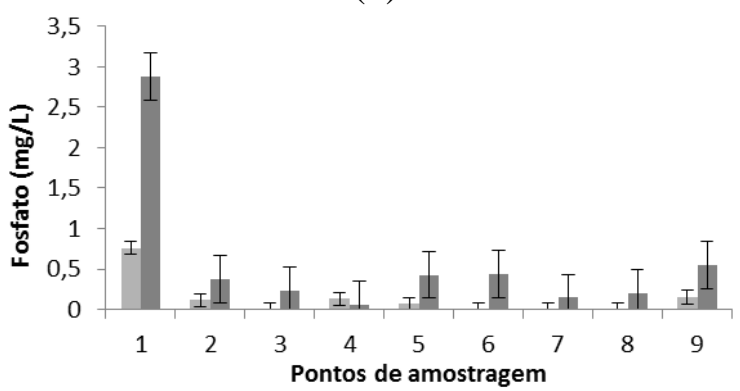

(d)

Período seco Período chuvoso

Figura 4. Valores médios de (a) turbidez, (b) coliformes, (c) nitrato e (d) fosfato nos diferentes pontos de monitoramento na micro-bacia do Córrego Banguelo.

A análise do IQA $A_{N S F}$ indicou que a qualidade da água foi melhor no período chuvoso, sendo observada apenas no ponto 8 uma qualidade da água ruim (Córrego Bom Jesus Figura 1). Nos demais pontos de monitoramento, a qualidade foi média ou boa (Tabela 1).

Tabela 1. Resultados médios para o IQA $A_{\mathrm{NSF}}$ da água coletada no córrego Banguelo no período de setembro de 2008 a julho de 2009.

\begin{tabular}{c|cccccc}
\hline $\begin{array}{c}\text { Ponto de } \\
\text { monitoramento }\end{array}$ & $\begin{array}{l}\text { IQA }_{\text {NSF }} * \\
\text { período } \\
\text { seco }\end{array}$ & $\begin{array}{l}\text { Qualidade } \\
\text { da Água }\end{array}$ & $\begin{array}{l}\text { IQA }_{\text {NSF }} * \\
\text { período } \\
\text { chuvoso }\end{array}$ & $\begin{array}{l}\text { Qualidade } \\
\text { da Água }\end{array}$ & $\begin{array}{l}\text { IQA }_{\text {NSF }}^{*} \\
\text { Médio }\end{array}$ & $\begin{array}{l}\text { Qualidade } \\
\text { da Água }\end{array}$ \\
\hline 1 & 28,4 & Ruim & 56,8 & Médio & 28,4 & Ruim \\
2 & 38,9 & Ruim & 57,1 & Médio & 48,1 & Ruim \\
3 & 37,8 & Ruim & 60,1 & Médio & 48,9 & Ruim \\
4 & 56,2 & Médio & 71,2 & Bom & 63,7 & Médio \\
5 & 39,6 & Ruim & 73,7 & Bom & 56,7 & Médio \\
6 & 33,9 & Ruim & 58,1 & Médio & 46,0 & Ruim \\
7 & 42,6 & Ruim & 62,3 & Médio & 52,5 & Médio \\
8 & 33,9 & Ruim & 44,6 & Ruim & 37,4 & Ruim \\
9 & 36,3 & Ruim & 60,7 & Médio & 36,3 & Ruim \\
\hline
\end{tabular}

* Valores de Índice de Qualidade da Água: Excelente $\left(90<\mathrm{IQA}_{\mathrm{NSF}}<100\right)$, Bom $\left(70<\mathrm{IQA}_{\mathrm{NSF}}<90\right)$, Médio $\left(50<\mathrm{IQ} A_{\mathrm{NSF}}<70\right)$, Ruim $\left(25<\mathrm{IQ} A_{\mathrm{NSF}}<50\right)$, Muito Ruim $\left(0<\mathrm{IQA}_{\mathrm{NSF}}<25\right)$. 
PONTES, P. P.; MARQUES, A. R.; MARQUES, G. F. Efeito do uso e ocupação do solo na qualidade da água na micro-bacia do Córrego Banguelo - Contagem. Ambi-Agua, Taubaté, v. 7, n. 3, p. 183-194, 2012. (http://dx.doi.org/10.4136/ambi-agua.962)

No período seco, a qualidade da água foi ruim em quase todos os pontos de monitoramento. Assim, embora alguns parâmetros tenham apresentado uma pequena deterioração no período chuvoso (devido ao OD e fosfato, principalmente), foi possível observar uma melhoria do IQA $\mathrm{NSF}_{\mathrm{N}}$ nesse período.

\subsection{Efeito do uso e ocupação do solo na qualidade da água}

A maior parte das margens do córrego Banguelo encontrou-se ocupada, particularmente por moradias distribuídas em loteamentos tradicionais ou em chácaras. Próximos aos pontos 1 e 2 de monitoramento da água, foram observadas duas nascentes, sendo que uma delas estava canalizada e dentro de um estabelecimento industrial (Figura 1). Atividades pecuárias e agrícolas em pequena escala foram observadas no entorno do córrego, sendo os pontos 2 , 3, 4 e 5 localizados dentro de uma fazenda. Foram observados diversos focos de erosão próximos ao córrego, consequência do desmatamento, e lançamento de esgoto devido à expansão urbana sem planejamento. Fragmentos florestais remanescentes foram observados na cabeceira do córrego, com diversas áreas de clareiras desmatadas para utilização rural, principalmente próximo às margens do curso d'água. $\mathrm{O}$ ponto 4 , no afluente do córrego estava recebendo água das nascentes ainda protegidas por vegetação arbórea de um destes fragmentos florestais (Figura 1). O ponto 7 , recebendo água de uma pequena lagoa (Figura 1), e os pontos 8 e 9, no córrego Bom Jesus canalizado, estavam em áreas mais urbanizadas.

O levantamento florístico (Tabela 2) mostrou que a maior parte da margem do córrego se encontrava constituído por plantas pioneiras do estrato herbáceo-arbustivo, e por secundárias e clímaxes do estrato arbustivo e arbóreo. Na nascente do afluente do córrego também se observou duas espécies de pteridófitas, Blechnum brasiliensis Desv. (Blechnaceae) e Cyathea delgadii Sternb. (Cyatheaceae), além das espécies arbóreas. Nas áreas de baixadas, bem úmidas ou alagadas, foram comuns as macrófitas das famílias Polygonoceae, Pontederiaceae e Thyphaceae (Tabela 2). Nas margens do córrego das áreas mais urbanizadas as gramíneas (Poaceae) foram predominantes e invasoras como Ricinus communis (mamona).

Tabela 2. Espécies do estrato herbáceo, arbustivo e arbóreo encontradas as margens e nascentes do córrego Banguelo (Contagem) e suas respectivas formas de vida.

\begin{tabular}{l|l|l}
\hline \multicolumn{1}{c|}{ Famílias } & \multicolumn{1}{|c}{ Espécies } & Formas de vida \\
\hline APOCYNACEAE & Asclepias curassavica $\mathrm{L}$ & Erva daninha \\
\hline & Artemisia vulgaris $\mathrm{L}$ & Erva \\
& Baccharis crispa Spreng & Erva \\
& Bidens alba $(\mathrm{L}.) \mathrm{DC}$ & Erva daninha \\
ASTERACEAE & Cyrtocymura scorpioides $($ Lam.) H. Rob & Erva \\
& Pterocaulon virgatum $(\mathrm{L}$.$) DC$ & Erva daninha \\
\hline BURSERACEAE & Protium heptaphyllum (Aubl.) Marchand & Árvore \\
\hline
\end{tabular}


PONTES, P. P.; MARQUES, A. R.; MARQUES, G. F. Efeito do uso e ocupação do solo na qualidade da água na micro-bacia do Córrego Banguelo - Contagem. Ambi-Agua, Taubaté, v. 7, n. 3, p. 183-194, 2012. (http://dx.doi.org/10.4136/ambi-agua.962)

\begin{tabular}{|c|c|c|}
\hline $\begin{array}{l}\text { CYPERACEAE } \\
\text { EUPHORBIACEAE }\end{array}$ & $\begin{array}{l}\text { Rhynchospora corymbosa }(\mathrm{L} .) \text { Britton } \\
\text { Ricinus communis } \mathrm{L}\end{array}$ & $\begin{array}{l}\text { Erva daninha } \\
\text { Arbusto invasor }\end{array}$ \\
\hline FABACEAE & $\begin{array}{l}\text { Dalbergia nigra (Vell.) Alemão ex Benth. } \\
\text { Mimosa bimucronata (DC.) Kuntze } \\
\text { Ormosia arborea (Vell.) Harms } \\
\text { Piptadenia gonoacantha (Mart.) J.F. Macbr }\end{array}$ & $\begin{array}{l}\text { Árvore } \\
\text { Arbusto } \\
\text { Árvore } \\
\text { Árvore }\end{array}$ \\
\hline LAURACEAE & Nectandra oppositifolia Nees & Árvore \\
\hline MELASTOMATACEAE & Miconia chamissois Naudin & Arbusto \\
\hline ONAGRACEAE & Ludwigia elegans (Cambess.) H. Hara & Erva daninha \\
\hline PERACEAE & Pera glabrata (Schott) Poepp. ex Baill & Árvore \\
\hline POACEAE & $\begin{array}{l}\text { Echinochloa cru-sgalli (L.) P.Beauv } \\
\text { Homolepis glutinosa (Sw.) Zuloaga \& Soderstr } \\
\text { Ichnanthus pallens (Sw.) Munro ex Benth. } \\
\text { Lasiacis sorghoidea (Desv. ex Ham.) Hitchc. \& Chase }\end{array}$ & $\begin{array}{l}\text { Erva } \\
\text { Erva } \\
\text { Erva } \\
\text { Erva }\end{array}$ \\
\hline POLYGALACEAE & $\begin{array}{l}\text { Polygala paniculata } \mathrm{L} \\
\text { Polygala monninoides Kunth }\end{array}$ & $\begin{array}{l}\text { Erva } \\
\text { Erva }\end{array}$ \\
\hline POLYGONACEAE & $\begin{array}{l}\text { Polygonum acuminatum Kunt } \\
\text { Polygonum ferrugineum Wedd } \\
\text { Polygonum punctatum Elliott }\end{array}$ & $\begin{array}{l}\text { Macrófita } \\
\text { Macrófita } \\
\text { Macrófita }\end{array}$ \\
\hline PONTEDERIACEAE & $\begin{array}{l}\text { Heteranthera reniformis Ruiz \& Pav } \\
\text { Eichhornia crassipes (Mart.) Solms }\end{array}$ & $\begin{array}{l}\text { Macrófita } \\
\text { Macrófita }\end{array}$ \\
\hline $\begin{array}{l}\text { RUBIACEAE } \\
\text { SOLANACEAE } \\
\text { TYPHACEAE }\end{array}$ & $\begin{array}{l}\text { Borreria capitata (Ruiz \& Pav.) DC. } \\
\text { Solanum americanum Mill. } \\
\text { Typha domingensis Pers }\end{array}$ & $\begin{array}{l}\text { Erva } \\
\text { Erva } \\
\text { Macrófita }\end{array}$ \\
\hline URTICACEAE & $\begin{array}{l}\text { Cecropia hololeuca Miq. } \\
\text { Cecropia pachystachya Trécul }\end{array}$ & $\begin{array}{l}\text { Árvore } \\
\text { Árvore }\end{array}$ \\
\hline VERBENACEAE & $\begin{array}{l}\text { Lantana camara } \mathrm{L} . \\
\text { Stachytarpheta canescens Kunth }\end{array}$ & $\begin{array}{l}\text { Subarbusto } \\
\text { Erva }\end{array}$ \\
\hline
\end{tabular}

A relação entre uso e ocupação do solo e qualidade da água pode ser observada através da análise dos diferentes locais de monitoramento, a exemplo dos pontos 1 e 4 , que estavam próximos às duas nascentes da micro-bacia do córrego Banguelo. $\mathrm{O}$ efeito da poluição causada pelo efluente industrial lançado na nascente próxima do ponto 1 foi constatado pela deterioração da qualidade da água. Observou-se que o lançamento de um efluente industrial contribuiu para um baixo valor de IQA $\mathrm{NSF}_{\mathrm{NS}}$ e elevados valores para $\mathrm{DBO}_{5}, \mathrm{DQO}$, coliformes, 
PONTES, P. P.; MARQUES, A. R.; MARQUES, G. F. Efeito do uso e ocupação do solo na qualidade da água na micro-bacia do Córrego Banguelo - Contagem. Ambi-Agua, Taubaté, v. 7, n. 3, p. 183-194, 2012. (http://dx.doi.org/10.4136/ambi-agua.962)

nitrato e fosfato em relação aos outros pontos de monitoramento do córrego. No entanto, a nascente próxima ao ponto 4 , que está protegida por vegetação, contribuiu para uma melhor

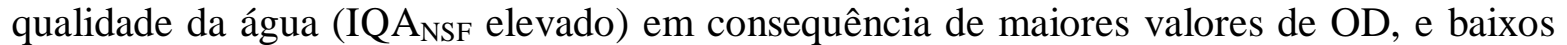
valores para fosfato, nitrato, $\mathrm{DBO}_{5}, \mathrm{DQO}$ e concentração de coliformes termotolerantes. A vegetação ripária pode contribuir para remoção de nitrato, fósforo, pesticidas dentre outros poluentes (Evans et al., 1996; Souza et al., 2004), devendo ser mantida ou recuperada.

O efeito do uso e ocupação do solo na qualidade da água pode ser observado ao longo

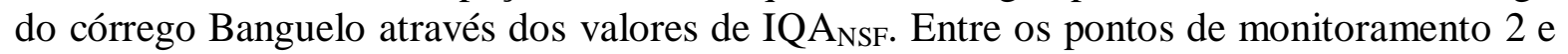
3 observou-se que a presença de macrófitas às margens do córrego, principalmente da espécie Typha domingensis (taboa), Eichhornia crassipes (aguapé) e das espécies Polygonum (erva-de-bicho), que contribuíram junto ao afluente, para melhorar a qualidade da água do córrego Banguelo no ponto 5 (Tabela 1). A partir desses pontos ocorreu um aumento no valor do $\mathrm{IQA}_{\mathrm{NSF}}$ e melhoria geral da qualidade da água. Tal resultado aponta para o potencial benefício no emprego de wetlands e pequenos alagados para melhoria na qualidade da água em regiões parcialmente urbanizadas, especialmente para reduzir a poluição causada pelo escoamento de drenagem pluvial. As regiões de transição solo/água com macrófitas aquáticas, também chamadas wetlands ou terras úmidas são ecótonos e têm papel significativo em processar nutrientes, adsorver e absorver substâncias tóxicas, e em regular o fluxo hidráulico (Marques, 1999; Diniz et al., 2005).

Entre os pontos 5 e 6, as margens do córrego Banguelo apresentaram-se parcialmente urbanizadas, observando-se a maior parte da região ocupada por moradias. A substituição de áreas recobertas por vegetação por áreas impermeabilizadas ocasiona um aumento do volume de água que escoa no período de chuvas. Além disso, o lançamento de esgotos e lixo nos córregos agrava o problema de qualidade das águas, como pode ser observado através dos valores baixos de IQA $A_{N S F}$. Nota-se a redução no OD do ponto 5 para o ponto 6 , resultado do processo de autodepuração do córrego, porém, tal efeito é mais significativo na estação seca, em função das menores vazões nessa época.

Do ponto 4 para o ponto 5 verificou-se um pico na presença de coliformes, consequência de um provável lançamento de efluentes domésticos naquele trecho. Entretanto, percebe-se que o aumento nos coliformes é maior na estação chuvosa, indicativo da presença de escoamento pluvial com contaminação de dejetos, além de uma possível influência de fossas sépticas ali presentes. Esse trecho é caracterizado por residências sem coleta de esgotos, e presença de quintais com criação de animais.

A ocorrência de vegetação herbácea, especialmente gramínea às margens do córrego, e de um lago entre os pontos 6 e 7, pode ter sido um fator que contribuiu para o aumento no valor de IQA $A_{N S F}$. As maiores concentrações de $\mathrm{OD}$ e os menores valores de $\mathrm{DBO}_{5}$ no ponto 7 se deveram, provavelmente, à presença do lago, que pode funcionar como um wetland natural, apresentando uma contribuição mais significativa no processo de autodepuração (Ceballos et al., 2001; Von Sperling e Chernicharo, 2006). Nos pontos de monitoramento 8 (córrego Bom Jesus) e 9 (córrego Bom Jesus após receber a contribuição do córrego Banguelo) observou-se uma diminuição no IQA $\mathrm{NSF}_{\mathrm{N}}$ e deterioração na qualidade da água, possivelmente devido à maior presença de residências nessa área. Esse resultado também indica uma possível contribuição negativa do Banguelo para a qualidade da água do córrego Bom Jesus, e em último caso para o reservatório da Pampulha.

\section{CONCLUSÕES}

A análise do Índice de Qualidade da Água ( $\mathrm{IQA}_{\mathrm{NSF}}$ ) na micro-bacia do córrego Banguelo indicou que a qualidade da água oscilou entre média e ruim no período seco nos 
pontos de monitoramento avaliados. A qualidade da água foi melhor no período chuvoso, tendo-se observado apenas um ponto de monitoramento com qualidade da água ruim no córrego Bom Jesus. Os resultados indicaram que a poluição do córrego Banguelo tem início na região próxima à sua nascente (ponto 1), com lançamento de efluente industrial e ocorrência de níveis baixos de oxigênio dissolvido, presença de matéria orgânica e nutrientes na água monitorada. A poluição das áreas urbanizadas contribuiu para uma maior deterioração da qualidade das águas na micro-bacia do Banguelo, prejudicando não só a população, pelo aspecto e qualidade de suas águas, como também o córrego, que passa a contribuir para a poluição do reservatório da Pampulha, acelerando a eutrofização e deterioração da qualidade da água.

Apesar dos resultados de qualidade da água encontrados, foi possível verificar melhorias nas áreas onde a vegetação ripária encontrou-se menos degradada, destacando a contribuição de espécies como macrófitas na depuração da água e de outras espécies terrestres na proteção contra erosão e aporte de sedimentos ao córrego. Tal contribuição produziu uma recuperação do córrego para melhores patamares de qualidade da água de forma relativamente rápida, o que é percebido comparando os pontos $1 \mathrm{e} 2$. Tais resultados permitem concluir que, apesar dos impactos ambientais presentes no córrego do Banguelo, ainda existem processos naturais (físico-químicos e biológicos) capazes de absorver parte da carga de poluentes lançada. Nesse sentido, ações de coleta e tratamento dos efluentes industriais e domésticos, aliados à preservação da vegetação ripária restante, se apresentam como medidas de grande potencial na melhoria da qualidade das águas do córrego Banguelo e no próprio reservatório da Pampulha. O estudo e aplicação de medidas similares nos demais cursos d'água que drenam para o reservatório da Pampulha constitui, dessa forma, o ponto de partida para a solução do problema de eutrofização ali presente.

\section{AGRADECIMENTOS}

Os autores agradecem à FAPEMIG pelo financiamento do projeto (processo APQ4016-6.01/07) e pelas bolsas concedidas, à Secretaria do Meio Ambiente da Prefeitura de Belo Horizonte, Fundação Zoo-Botânica e ao PROPAM (Programa de Recuperação e Desenvolvimento Ambiental da Bacia da Pampulha) pelo auxílio à pesquisa.

\section{REFERÊNCIAS}

AWWA; APHA; WEF. Standard methods for the examination of water and wastewater. $21^{\text {th }}$ edition. Washington, 2005. $1496 \mathrm{p}$.

CEBAllOS, B. S. O.; KONIG, A.; ROLIM, H. O.; ARAÚJO, M. L.; GUIMARAES, A.O. Efeito do represamento na qualidade da água de um rio impactado por esgotos - rio bodocongó, campina grande, PB. In: CONGRESSO BRASILEIRO DE ENGENHARIA SANITÁRIA E AMBIENTAL, 21., 2001, Joao Pessoa. Proceedings... Joao Pessoa: ABESA, 2001.

DINIZ, C. R.; CEBAllos, B. S. O. de; BARBOSA, J. E. L.; KONIG, A. Uso de macrófitas aquáticas como solução ecológica para melhoria da qualidade de água. Revista Brasileira de Engenharia Agrícola e Ambiental, v. 9, suplemento, p. 226230, 2005.

EVANS, R.; GILLIAM, J. W.; LILLY, J. P. Wetlands and water quality. North Carolina Cooperative Extension Service, 1996. Disponível em: <http://www.bae.ncsu.edu/ programs/extension/evans/ag473-7.html>. Acesso em: ago. 2012. 
FRANCO, R. A. M.; VANZELA, L. S.; HERNANDEZ, F. B. T. Avaliação biológica da qualidade da água para irrigação do Córrego três barras, Marinópolis, SP. In: CONGRESSO NACIONAL DE IRRIGAÇÃO E DRENAGEM (CONIRD), 16. , 2006, Goiânia. Proceedings. Goiânia: ABID, 2006.

FRIESE, K.; SCHMIDT, G.; LENA, J. C.; NALINI, JR., H. A.; ZACHMANN, D. W. Anthropogenic influence on the degradation of an urban lake - The Pampulha reservoir in Belo Horizonte, Minas Gerais, Brazil. Limnologica - Ecology and Management of Inland Waters, v. 40, n. 2, p. 114-125, 2010. http://dx.doi.org/10.1016/j.limno.2009.12.001

INSTITUTO BRASILEIRO DE GEOGRAFIA E ESTATÍSTICA - IBGE. Departamento da População e Indicadores Sociais. Características da população e dos domicílios: resultados do universo. Rio de Janeiro, 2000. 520 p.

MARQUES, D. M. Terras úmidas construídas de fluxo subsuperficial. In: CAMPOS, J. R. (Coord.). Tratamento de esgotos sanitários por processo anaeróbio e disposição controlada no solo. Rio de Janeiro: ABES, 1999. p. 409-435.

PROPAM - PROGRAMA DE RECUPERAÇÃO E DESENVOLVIMENTO AMBIENTAL DA BACIA DA PAMPULHa. Relatório técnico. Belo Horizonte, 2001.

RIETZLER, A. C.; FONSECA, A. L.; LOPES, G. P. Heavy metals in tributaries of Pampulha Reservoir, Minas Gerais. Brazilian Journal of Biology, v. 61, n. 3, p. 363 370, 2001.http://dx.doi.org/10.1590/S1519-69842001000300004

SABINO, C. V. S.; KASTNER, G. F.; AMARAL, A. M.; LEITE, S. C. A.; CARVALHO, R. P.; SILVA, I. S. Estudo da biodisponibilidade de metais nos sedimentos da Lagoa da Pampulha. Química Nova, v. 27, n. 2, p. 231-235, 2004. http://dx.doi.org/10.1590/S0100-40422004000200011

SOUZA, J. T.; VAN HAANDEL, A.; LIMA, E. P. C.; HENRIQUE, I. N. Utilização de wetland construído no pós-tratamento de esgotos domésticos pré-tratados em reator UASB. Engenharia Sanitária e Ambiental, v. 9, n. 4, p. 285-290, 2004. http://dx.doi.org/10.1590/S1413-41522004000400004

VON SPERLING, M.; CHERNICHARO, C. A. L. Biological wastewater treatment in warm climate regions. London: IWA Publishing, 2006. 810p. Vol. 1.

XAVIER, C. F. Avaliação da influência do uso e ocupação do solo e de características geomorfológicas sobre a qualidade das águas de dois reservatórios da região metropolitana de Curitiba - Paraná. 2005. 167f. Dissertação (Mestrado em Ciências do Solo) - Universidade Federal do Paraná, Curitiba, 2005. 